CLINICAL STUDY

\title{
Effects of transdermal testosterone or oral dydrogesterone on hypoactive sexual desire disorder in transsexual women: results of a pilot study
}

\author{
Desiree Kronawitter, Louis J Gooren ${ }^{1}$, Hendryk Zollver, Patricia G Oppelt, Matthias W Beckmann, Ralf Dittrich \\ and Andreas Mueller
}

Department of Obstetrics and Gynecology, Erlangen University Hospital, Universitätsstrasse 21-23, D-91054 Erlangen, Germany and ${ }^{1}$ Department of Endocrinology, Free University Medical Center (VUMC), 1007-MB Amsterdam, The Netherlands

(Correspondence should be addressed to A Mueller; Email: andreas.mueller@uk-erlangen.de)

\begin{abstract}
Objective: It has been reported that hypoactive sexual desire disorder (HSDD) affects one-third of transsexual women (defined as postoperative male-to-female transsexuals) receiving estrogen replacement whose bioavailable androgen levels are lower than in ovulating women and comparable with those in surgically postmenopausal women. The aim of this study was to evaluate the efficacy of transdermal testosterone treatment and of oral dydrogesterone in transsexual women with HSDD receiving estrogens.

Methods: Seven transsexual women with HSDD were treated with a testosterone patch and nine transsexual women with HSDD were treated with oral dydrogesterone over 24 weeks. The primary end point was the change in the brief profile of female sexual function (B-PFSF) score. Secondary end points were changes in hormonal parameters and side effect assessments.

Results: A significant increase in total testosterone and free testosterone levels was observed in the group receiving transdermal testosterone. At 24 weeks, there was a significant improvement in the B-PFSF score showing an improvement in sexual desire among transsexual women treated with the testosterone patch, whereas no change in the B-PFSF score was observed in transsexual women treated with oral dydrogesterone. No side effects were reported.

Conclusions: In this pilot study, sexual desire in transsexual women improved significantly after treatment with the testosterone patch, without noticeable side effects.
\end{abstract}

European Journal of Endocrinology 161 363-368

\section{Introduction}

It has recently been reported that one in three transsexual women (defined as postoperative maleto-female transsexuals) receiving estrogen replacement suffers from hypoactive sexual desire disorder (HSDD) (1). It is now widely believed that testosterone has a role in female sexual desire (2-4). The role of testosterone in motivational aspects of sexuality such as sexual desire $(5,6)$ and activity $(7)$ is now well documented. It is therefore possible that a lack of testosterone production and, in addition, the effect of continuous estrogen treatment in producing a marked increase in sex hormone-binding globulin (SHBG), binding adrenal androgens, might induce a state of severe hypoandrogenemia and might lead to symptoms of HSDD in these women.

We have reported previously that the levels of total testosterone (TT) and (as the level of SHBG significantly increases) calculated free testosterone (cFT) declined by up to $97 \%$ in transsexuals treated with estrogens (8-10). In addition, it has been reported that two out of three transsexual women have FT levels below the concentrations found in ovulating women (11). However, no significant correlation between androgen levels and measures of sexual desire have been detected in transsexual women and control women $(1,12)$. Despite this, there is ample evidence that treatment with testosterone increases sexual desire and activity in surgically menopausal women with HSDD (13-19). In some studies, statistically significant correlations have been observed between changes in sexual desire and testosterone serum concentrations after treatment with a testosterone patch $(13,14)$. Women suffering from low libido in the natural menopause may also benefit from testosterone treatment while taking estrogens (20, 21) or not taking estrogens (22). Some transsexual women wish to receive treatment with a progestational compound, as they believe that addition of this female hormone will bolster the feminization process, but 
there is no evidence in support of this contention (23). Depending on their chemical structure, synthetic progestins have partial androgenic or anti-androgenic properties, but dydrogesterone is devoid of androgenic or anti-androgenic action.

This aim of this pilot study was to evaluate the effect of testosterone and of medication with a progestin on sexual desire in transsexual women with HSDD, using the brief profile of female sexual function (B-PFSF), which was developed and validated to provide good discrimination between women who have HSDD and those who do not (24).

\section{Subjects and methods}

\section{Patients and sex hormone treatment}

In our department, transsexual women who had undergone surgical sex reassignment (SRS) were normally treated with $10 \mathrm{mg}$ i.m. estradiol-17 $\beta\left(\mathrm{E}_{2}\right)$ valerate every 2 weeks (Estradiol-Depot $10 \mathrm{mg}$; Jenapharm, Jena, Germany). Routine monitoring of our patients in the first year after SRS: all of transsexuals were interviewed regarding their medical history and were tested for HSDD using the B-PFSF questionnaire 1 year after their initial SRS. None of them analyzed for this study was suffering from thrombosis or other vascular diseases. Transsexual women with complications in their postoperative period and those who were not satisfied with the aesthetic and functional results after SRS were not included in the analysis. Patients receiving other medications were also not included. All of the patients continued their normal diet throughout the observation period. Thereafter, the study population consists of 64 transsexual women. All transsexual women had their SRS in the years 2006 and 2007. A B-PFSF score $\leq 20$ reportedly indicates clinically relevant HSDD (24). Some transsexual women were treated with a transdermal patch administering testosterone at $300 \mu \mathrm{g} /$ day (Intrinsa TTS, Procter \& Gamble Pharmaceuticals; Darmstadt, Germany) or others with oral dydrogesterone $10 \mathrm{mg}$ /day (Duphaston $10 \mathrm{mg}$; Solvay Arzneimittel, Hanover, Germany), depending on their own preference. No randomization was done. The patients were monitored over a 24-week period and were seen every 12 weeks for clinical evaluation. They all underwent regularly monitoring, including hormonal analysis every 24 weeks, complete blood count, and serum chemistry profile, and transsexuals with significant abnormalities in any of these parameters were not included in the analysis. Any other necessary medical intervention was recorded and documented. At the end of the study period after 24 weeks, all of the participating transsexual women were evaluated again using the B-PFSF. All data files were evaluated anonymously and analyzed retrospectively. Institutional review board approval was obtained.

\section{Hormone measurements}

Before and after the 24-week study period, blood was sampled in the morning between 0800 and $1000 \mathrm{~h}$ to measure serum levels of LH, FSH, TT, DHEAS, estradiol (E), prolactin (PRL), and SHBG. In addition, the blood count, serum chemistry profile, and liver enzymes - aspartate aminotransferase, alanine aminotransferase, $\gamma$-glutamyl transferase, cholesterol, and triglycerides - were regularly measured using routine clinical chemistry assessment.

All blood samples were immediately assayed for hormone parameters in a routine laboratory test using established commercial assays routinely monitored by participation in external quality control programs. All of the assays were carried out in a routine diagnostic endocrine laboratory. TT, DHEAS, SHBG, E, PRL, LH, and FSH were measured with chemiluminescent enzyme immunoassays (Immulite 2000; Siemens Medical Solutions Diagnostics Ltd, Bad Nauheim, Germany), as previously described in detail (25-32). For the TT-assay, the intraassay coefficients of variation $(\mathrm{CV})$ were $16.3,11.7$, and $10.0 \%$ at the levels of $0.93,2.98$, and $5.26 \mathrm{nmol} / \mathrm{l}$. The corresponding interassay CVs were 24.3, 13.0, and $10.3 \%$.

\section{Calculation of free testosterone}

Measuring TT, and in particular FT, in women is challenging (33-35). cFT was calculated using the formula provided by the International Society for the Study of the Aging Male (http://www.issam.ch/freetesto.htm), from TT and SHBG in the same sample, as described in detail by Vermeulen et al. 1999 (34), without taking the albumin concentration into account $(25,27)$.

\section{Brief profile of female sexual function}

The B-PFSF consists of seven items, Table 1. Each item is scored on a 6-point Likert scale, from 'always' to 'never'. The item scores were transformed (never $=0$ points; always $=5$ points) so that lower scores were indicative of poorer sexual function and higher distress. A total score for the B-PFSF is obtained by summing the scores for each item, resulting in a total score ranging from 0 to 35 , while a cut-off of 20 was found to be clinically relevant in categorizing women as possibly having HSDD or not (24).

\section{Statistical analysis}

Numerical variables are presented as mean \pm s.D., unless otherwise noted. Non-parametric statistical tests were used, which are based on ranks of observations and require no assumptions about the underlying distribution of data. Wilcoxon rank-sum tests were used to 
Table 1 Age, body mass index (BMI), and change in sexual desire using the brief profile of female sexual function (B-PFSF) of the analyzed transsexual women treated with the testosterone $300 \mu \mathrm{g} / \mathrm{day}$ patch or with dydrogesterone $10 \mathrm{mg} / \mathrm{day}$.

\begin{tabular}{|c|c|c|c|c|c|c|}
\hline & \multicolumn{3}{|c|}{ Testosterone $300 \mu \mathrm{g} /$ day patch } & \multicolumn{3}{|c|}{ Dydrogesterone $10 \mathrm{mg} / \mathrm{day}$} \\
\hline & Baseline $n=7$ & 24 Weeks $n=7$ & $P$ & Baseline $n=9$ & 24 Weeks $n=9$ & $P$ \\
\hline Age (years) & $46.14(12.94)$ & $46.43(12.70)$ & 0.18 & $44.22(6.18)$ & $44.78(6.16)$ & 0.25 \\
\hline $\mathrm{BMl}\left(\mathrm{kg} / \mathrm{m}^{2}\right)$ & $26.55(6.42)$ & $26.90(6.35)$ & 0.13 & $25.62(3.28)$ & $26.03(3.42)$ & 0.37 \\
\hline B-PFSF score & $15.14(3.38)$ & $22.43(3.64)$ & $0.017^{*}$ & $16.57(3.28)$ & $17.00(2.33)$ & 0.43 \\
\hline \multicolumn{7}{|l|}{ Final items of the B-PFSF } \\
\hline I felt like having sex & $1.57(0.53)$ & $3.00(0.82)$ & $0.016^{*}$ & $2.33(0.86)$ & $2.11(0.78)$ & 0.55 \\
\hline $\begin{array}{l}\text { I was unhappy about my } \\
\text { lack of interest in sex }\end{array}$ & $2.14(0.69)$ & $3.57(0.53)$ & $0.015^{\star}$ & $2.67(0.71)$ & $2.56(0.72)$ & 0.76 \\
\hline Getting aroused took forever & $2.00(0.58)$ & $3.14(0.38)$ & $0.014^{*}$ & $2.56(0.73)$ & $2.44(0.73)$ & 0.78 \\
\hline I felt sexually numb & $2.71(0.95)$ & $3.71(0.49)$ & $0.020^{*}$ & $2.22(0.44)$ & $2.67(0.71)$ & 0.17 \\
\hline $\begin{array}{l}\text { I felt disappointed by my } \\
\text { lack of interest in sex }\end{array}$ & $2.43(1.13)$ & $3.43(0.53)$ & $0.023^{*}$ & $2.33(0.50)$ & $2.67(0.50)$ & 0.20 \\
\hline I lacked sexual desire & $2.57(0.53)$ & $3.29(0.95)$ & $0.025^{\star}$ & $2.44(0.73)$ & $2.33(0.50)$ & 0.73 \\
\hline I reached orgasm easily & $1.71(0.76)$ & $2.14(0.90)$ & $0.046^{\star}$ & $1.67(0.50)$ & $1.89(0.33)$ & 0.17 \\
\hline
\end{tabular}

Data are shown as mean \pm S.D. *Considered significant. No differences were found when baseline parameters of both groups were compared $(P$ values were 0.69 for age; 0.71 for BMI; 0.52 for B-PFSF score; and 0.06; $0.16 ; 0.12 ; 0.19 ; 0.82 ; 0.70 ; 0.90$, for the different items of the B-PFSF score).

compare parameters at baseline and after 24 weeks of treatment in the different groups. Baseline parameters of both treatment groups were also compared using the Wilcoxon rank-sum test. Calculations were all performed by the SPSS program (version 16.0 for Windows; SPSS, Inc., Chicago, IL, USA). All hypothesis tests were two-sided. $P$ values $<0.05$ were considered statistically significant.

\section{Results}

Of the 64 healthy middle-aged transsexual women who were evaluated for HSDD using the B-PFSF, 18 transsexual women turned out to have a B-PFSF score $\leq 20$ and were categorized as having clinically relevant HSDD. This represents a prevalence of HSDD of $28 \%$ in the population studied. Two transsexuals were not included in the analysis because they changed their steroid medication. A total of 16 patient files were complete and were included in the analysis. Seven of the 16 women received treatment with the transdermal patch with testosterone $300 \mu \mathrm{g} /$ day for a minimum of 24 weeks, while the other nine received oral dydrogesterone $10 \mathrm{mg} /$ day for a minimum of 24 weeks. Changes in the anthropometric data and in the B-PFSF score are shown in Table 1. A significant increase in the B-PFSF score was observed in the transsexual women treated with the testosterone patch, while no changes occurred in the transsexual women treated with dydrogesterone. The hormonal profiles of both groups are shown in Table 2. A significant increase in TT and cFT levels was only observed in the group of transsexual women treated with the testosterone patch; no change was observed in the group treated with dydrogesterone. No differences were found when baseline parameters of both groups were compared. During the clinical evaluation every 12 weeks, no side effects were recorded in any of the transsexual women studied, and none of the participants discontinued the treatment. In the testosterone group six out of seven transsexuals (86\%) continued the treatment after 24 weeks, while in the dydrogesterone group only four out of nine transsexuals $(44 \%)$ continued the treatment after 24 weeks.

Table 2 Comparison of serum hormone levels of the analyzed transsexual women.

\begin{tabular}{|c|c|c|c|c|c|c|}
\hline & \multicolumn{3}{|c|}{ Testosterone $300 \mu \mathrm{g} /$ day patch } & \multicolumn{3}{|c|}{ Dydrogesterone $10 \mathrm{mg} /$ day } \\
\hline & Baseline $n=7$ & 24 Weeks $n=7$ & $P$ & Baseline $n=9$ & 24 Weeks $n=9$ & $P$ \\
\hline LH (IU/I) & $5.44(1.77)$ & $5.69(1.59)$ & 0.59 & $4.24(1.39)$ & $5.20(1.80)$ & 0.17 \\
\hline $\mathrm{FSH}(\mathrm{IU} / \mathrm{I})$ & $3.66(1.06)$ & 3.94 (1.39) & 0.89 & $5.61(2.30)$ & $6.51(1.67)$ & 0.44 \\
\hline TT (nmol/l/) & $0.54(0.22)$ & $2.35(0.47)$ & $0.018^{*}$ & $0.61(0.39)$ & $0.70(0.39)$ & 0.57 \\
\hline $\mathrm{cFT}(\mathrm{nmol} / \mathrm{l})$ & $0.0034(0.002)$ & $0.015(0.002)$ & $0.018^{\star}$ & $0.005(0.005)$ & $0.009(0.011)$ & 0.26 \\
\hline DHEAS $(\mu \mathrm{mol} / \mathrm{l})$ & $3.50(1.75)$ & $4.13(2.00)$ & 0.99 & $3.84(1.38)$ & $3.77(1.37)$ & 0.59 \\
\hline $\mathrm{E}(\mathrm{pmol} / \mathrm{l})$ & $680.71(221.67)$ & $699.58(212.38)$ & 0.55 & 708.86 (192.48) & $711.44(217.35)$ & 0.95 \\
\hline Prolactin (mIU/l) & $203.82(86.33)$ & $179.31(54.45)$ & 0.99 & 285.73 (158.37) & $253.21(140.69)$ & 0.19 \\
\hline SHBG $(\mathrm{nmol} / \mathrm{l})$ & $145.14(27.56)$ & $137.52(22.25)$ & 0.31 & $134.12(44.46)$ & $125.81(45.57)$ & 0.48 \\
\hline
\end{tabular}

Data are shown as mean \pm S.D. *Considered significant. No differences were found when baseline parameters of both groups were compared $(P$ values were 0.15 for $\mathrm{LH}$; 0.06 for $\mathrm{FSH}$; 0.70 for TT; 0.51 for CFT; 0.67 for DHEAS; 0.78 for E; 0.23 for prolactin; and 0.57 for SHBG). 


\section{Discussion}

To the best of our knowledge, this pilot study is the first to analyze the potential benefit of transdermal testosterone or oral dydrogesterone in the treatment of HSDD in transsexual women.

Using the B-PFSF to distinguish between women who have HSDD and those who do not, about $28 \%$ of the transsexual women in this study appeared to be suffering from HSDD. This finding is in agreement with the prevalence of HSDD among transsexuals reported in earlier studies (1), and remarkably it is also in accordance with the prevalence of HSDD reported in surgically postmenopausal women (36).

This study shows that testosterone therapy is effective in the treatment of HSDD in transsexual women receiving cross-sex hormone therapy with $\mathrm{E}_{2}$ valerate, while treatment with dydrogesterone had no observable effect. Efficacy was measured only for 24 weeks, which appears to be sufficiently long, as efficacy has previously been reported to reach a plateau at 24 weeks (37).

The levels of TT and cFT were significantly lower in transsexual women in comparison with ovulating women $(1,11)$. Transsexual women should therefore be compared with women after surgical menopause, who show similar testosterone levels. Previous studies have shown that women who had undergone surgical or natural menopause who were suffering from HSDD and were treated with a testosterone patch experienced a significant increase in sexual activity and desire (13-22). More than $85 \%$ of those who reported a benefit wished to continue testosterone treatment (21).

The findings of the present study are consistent with other studies that have shown that the side-effect profile of the testosterone patch appears to be acceptable to women receiving estrogen treatment and those who have undergone natural menopause and are taking estrogens with a progestin, as well as those being treated with testosterone alone $(17,19,20,22)$. Although the evidence of the potential benefit of testosterone treatment in women suffering from HSDD is very convincing, there has been a lack of such data for treatment options in transsexual women.

The present study also investigated the effects of dydrogesterone on HSSD, as some transsexual women strongly believe that progestins are a necessary addition to estrogens in their feminization process (23). Transsexuals often believe that treatment with progestins has positive effects on breast growth and libido, but to our knowledge there has been no scientific proof of this assumption. The use of progestin as part of the endocrine treatment regimen for male-to-female transsexuals is a matter of controversy, and a clinical effect of progestins has not been evident in small observational studies (38). However, advantages have been observed in some patients with abnormal psychological irritability and mammary tenderness
(39). The present study did not provide any evidence that dydrogesterone had a positive effect on sexual desire among transsexual women.

In the follow-up of hormonal parameters in both groups, the levels of SHBG, LH, FSH, DHEAS, estradiol, and PRL showed no clear patterns of change over time. However, there was a significant increase in TT and cFT in the group of transsexuals treated with a testosterone patch. No side effects were reported in any of the transsexual women.

This investigation was a pilot study. Neither randomization nor blinding was performed. In addition, the number of transsexual women included was small, and the power of the study may be limited. Nevertheless, the use of a patch delivering $300 \mu \mathrm{g}$ testosterone per day significantly improved sexual desire in transsexual women who were receiving cross-sex hormone therapy with $\mathrm{E}_{2}$ valerate, while treatment with dydrogesterone was not effective. Prospectively controlled and randomized studies are needed to provide greater insight into treatment options for HSDD in transsexual women and to investigate the potential risks of long-term use of testosterone. Furthermore, the clinical relevance of the changes in sexual desire has to be confirmed.

\section{Declaration of interest}

There is no conflict of interest that could be perceived as prejudicing the impartiality of the research reported.

\section{Funding}

This research did not receive any specific grant from any funding agency in the public, commercial, or not-for-profit sector.

\section{Author contribution statement}

Desiree Kronawitter: medical care of the patients, wrote the manuscript: Louis J Gooren: correction of the manuscript: Hendryk Zollver: medical care of the patients, patient files analysis; Patricia G Oppelt: medical care of the patients, patient files analysis; Matthias $W$ Beckmann: medical care of the patients; Ralf Dittrich: laboratory methods; Andreas Mueller: wrote the manuscript, statistical evaluations.

\section{References}

1 Elaut E, De Cuypere G, De Sutter P, Gijs L, Van Trotsenburg M, Heylens G, Kaufman JM, Rubens R \& T'Sjoen G. Hypoactive sexual desire in transsexual women: prevalence and association with testosterone levels. European Journal of Endocrinology $2008 \mathbf{1 5 8}$ 393-399.

2 Turna B, Apaydin E, Semerci B, Altay B, Cikili N \& Nazli O. Women with low libido: correlation of decreased androgen levels with female sexual function index. International Journal of Impotence Research 200517 148-153.

3 Santoro N, Torrens J, Crawford S, Allsworth JE, Finkelstein JS, Gold EB, Korenman S, Lasley WL, Luborsky JL, McConnell D, Sowers MF \& Weiss G. Correlates of circulating androgens in 
mid-life women: the study of women's health across the nation. Journal of Clinical Endocrinology and Metabolism $2005 \mathbf{9 0}$ $4836-4845$.

4 Davis SR, Davison SL, Donath S \& Bell RJ. Circulating androgen levels and self-reported sexual function in women. Journal of the American Medical Association 2005294 91-96.

5 Sherwin BB. Changes in sexual behavior as a function of plasma sex steroid levels in post-menopausal women. Maturitas 19857 225-233.

6 Guay A, Jacobson J, Munarriz R, Traish A, Talakoub L, Quirk F, Goldstein I \& Spark R. Serum androgen levels in healthy premenopausal women with and without sexual dysfunction: part B: reduced serum androgen levels in healthy premenopausal women with complaints of sexual dysfunction. International Journal of Impotence Research 200416 121-129.

7 McCoy NL \& Davison JM. A longitudinal study of the effects of menopause on sexuality. Maturitas 19857 203-210.

8 Mueller A, Binder H, Cupisti S, Hoffmann I, Beckmann MW \& Dittrich R. Effects on the male endocrine system of long-term treatment with gonadotropin-releasing hormone agonist and estrogens in male-to-female transsexuals. Hormone and Metabolic Research 200638 183-187.

9 Mueller A, Dittrich R, Binder H, Kuehnel W, Maltaris T, Hoffmann I \& Beckmann MW. High dose estrogen treatment increases bone mineral density in male-to female transsexuals receiving gonadotropin-releasing hormone agonist in the absence of testosterone. European Journal of Endocrinology 2005153 107-113.

10 Dittrich R, Binder H, Cupisti S, Hoffmann I, Beckmann MW \& Mueller A. Endocrine treatment of male-to-female transsexuals using gonadotropin-releasing hormone agonist. Experimental and Clinical Endocrinology \& Diabetes 2005113 586-592.

11 De Cuypere G, T'Sjoen G, Beerten R, Selvaggi G, De Sutter P, Hoebeke P, Monstrey S, Vansteenwegen A \& Rubens R. Sexual and physical health after sex reassignment surgery. Archives of Sexual Behavior $200534679-690$.

12 Dennerstein L, Dudley EC, Hopper JL \& Burger H. Sexuality, hormones and the menopausal transition. Maturitas $1997 \mathbf{2 6}$ 83-93.

13 Simon J, Braunstein G, Nachtigall L, Utian W, Katz M, Miller S, Waldbaum A, Bouchard C, Derzko C, Buch A, Rodenberg C, Lucas J \& Davis S. Testosterone patch increases sexual activity and desire in surgically menopausal women with hypoactive sexual desire disorder. Journal of Clinical Endocrinology and Metabolism $2005905226-5233$.

14 Buster JE, Kingsberg SA, Aguirre O, Brown C, Breaux JG, Buch A, Rodenberg CA, Wekselman K \& Casson P. Testosterone patch for low sexual desire in surgically menopausal women: a randomized trail. Obstetrics and Gynecology 2005105 944-952.

15 DeRogatis LR, Graziottin A, Blitzer J, Schmitt S, Koochaki PE \& Rodenberger C. Clinically relevant changes in sexual desire, satisfying sexual activity and personal distress as measured by the profile of female sexual function, sexual activity log, and personal distress scale in postmenopausal women with hypoactive sexual desire disorder. Journal of Sexual Medicine 20096 175-183.

16 Shifren JL, Braunstein GD, Simon JA, Casson PR, Buster JE, Redmond GP, Burki RE, Ginsburg ES, Rosen RC, Leiblum SR, Caramelli KE \& Mazer NA. Transdermal testosterone treatment in women with impaired sexual function after oophorectomy. New England Journal of Medicine 2000343 682-688.

17 Braunstein GD, Sundwall DA, Katz M, Shifren JL, Buster JE, Simon JA, Bachman G, Aguirre OA, Lucas JD, Rodenberger C, Buch A \& Watts NB. Safety and efficacy of a testosterone patch for the treatment of hypoactive sexual desire disorder in surgically menopausal women: a randomized, placebo-controlled trail. Archives of Internal Medicine 2005165 1582-1589.

18 Davis SR, van der Mooren MJ, van Lunsen RH, Lopes P, Ribot C, Rees M, Moufarege A, Rodenberg C, Buch A \& Purdie DW. Efficacy and safety of a testosterone patch for the treatment of hypoactive sexual desire disorder in surgically menopausal women: a randomized, placebo-controlled trail. Menopause 2006 13 387-396.
19 Davis S, Papalia MA, Norman RJ, O’Neil S, Redelman M, Williamson M, Stuckey BG, Wlodarczyk J, Gard'ner K \& Humberstone A. Safety and efficacy of a testosterone metereddose transdermal spray for treating decreased sexual satisfaction in premenopausal women: a randomized trial. Annals of Internal Medicine 2008148 569-577.

20 Shifren JL, Davis SR, Moreau M, Waldbaum A, Bouchard C, DeRogatis L, Derzko C, Bearnson P, Kakos N, O'Neil S, Levine S, Wekselman K, Buch A, Rodenberg C \& Kroll R. Testosterone patch for the treatment of hypoactive sexual desire disorder in naturally menopausal women: results from the INTIMATE NM1 Study. Menopause 200613 770-779.

21 Kingsberg S. Testosterone treatment for hypoactive sexual desire disorder in postmenopausal women. Journal of Sexual Medicine $20074227-234$.

22 Davis SR, Moreau M, Kroll R, Bouchard C, Panay N, Gass M, Braunstein GD, Hirschberg AL, Rodenberg C, Pack S, Koch H, Moufarege A, Studd J \& APHRODITE Study Team. Testosterone for low libido in postmenopausal women not taking estrogen. New England Journal of Medicine 2008359 2005-2017.

23 Gooren LJ, Giltay EJ \& Bunck MC. Long-term treatment of transsexuals with cross-sex hormones: extensive personal experience. Journal of Clinical Endocrinology and Metabolism 200893 19-25.

24 Rust J, Derogatis L, Rodenberg C, Koochaki P, Schmitt S \& Golombok S. Development and validation of a new screening tool for hypoactive sexual desire disorder: the brief profile of female sexual function (B-PFSF). Gynecological Endocrinology 200723 638-644.

25 Mueller A, Dittrich A, Cupisti S, Beckmann MW \& Binder H. Is it necessary to measure free testosterone to assess hyperandrogenemia in women? The role of calculated free and bioavailable testosterone Experimental and Clinical Endocrinology and Diabetes $2006114182-187$.

26 Mueller A, Dittrich R, Binder H, Hoffmann I, Beckmann MW \& Cupisti S. Evaluation of recommended markers for assessing hyperandrogenemia in women classified as having polycystic ovary syndrome (PCOS) according to the revised 2003 diagnostic criteria. European Journal of Medical Research 200611 540-544.

27 Mueller A, Cupisti S, Binder H, Hoffmann I, Beckmann MW \& Dittrich $\mathrm{R}$. The role of albumin in the calculation of free and bioavailable testosterone in women with hyperandrogenemia. In Vivo 200620 403-407.

28 Mueller A, Cupisti S, Binder H, Hoffmann I, Kiesewetter F, Beckmann MW \& Dittrich R. Endocrinological markers for assessment of hyperandrogenemia in hirsute women. Hormone Research 200767 35-41.

29 Cupisti S, Dittrich R, Binder H, Beckmann MW \& Mueller A. Evaluation of biochemical hyperandrogenemia and body mass index in women presenting with amenorrhea. Experimental and Clinical Endocrinology E Diabetes 2007115 298-302.

30 Cupisti S, Dittrich R, Binder H, Kajaia N, Hoffmann I, Maltaris T, Beckmann MW \& Mueller A. Influence of body mass index on measured and calculated androgen parameters in adult women with hirsutism and PCOS. Experimental and Clinical Endocrinology $\mathcal{E}$ Diabetes 2007115 380-386.

31 Cupisti S, Kajaia N, Dittrich R, Duezenli H, Beckmann MW \& Mueller A. Body mass index and ovarian function are associated with endocrine and metabolic abnormalities in women with hyperandrogenic syndrome. European Journal of Endocrinology 2008158 711-719.

32 Kajaia N, Binder H, Dittrich R, Oppelt PG, Flor B, Cupisti S, Beckmann MW \& Mueller A. Low sex hormone-binding globulin as a predictive marker for insulin resistance in women with hyperandrogenic syndrome. European Journal of Endocrinology 2007157 499-507.

33 Rosner W, Auchus RJ, Azziz R, Sluss PM \& Raff H. Position statement: utility, limitations, and pitfalls in measuring testosterone: an Endocrine Society position statement. Journal of Clinical Endocrinology and Metabolism 200792 405-413. 
34 Vermeulen A, Verdonck L \& Kaufmann JM. A critical evaluation of simple methods for the estimation of free testosterone in serum. Journal of Clinical Endocrinology and Metabolism $1999 \mathbf{8 4}$ 3666-3672.

35 Azziz R, Carmina E, Dewailly D, Diamanti-Kandarakis E, Escobar-Morreale HF, Futterweit W, Janssen OE, Legro RS, Norman RJ, Taylor AE \& Witchel SF. Position statement: criteria for defining polycystic ovary syndrome as a predominantly hyperandrogenic syndrome: an Androgen Excess Society guideline. Journal of Clinical Endocrinology and Metabolism 200691 $4237-4245$.

36 Leiblum SR, Koochaki PE, Rodenberg CA, Barton IP \& Rosen RC. Hypoactive sexual desire disorder in postmenopausal women: US results from the Women's International Study of Health and Sexuality (WISHeS). Menopause 200613 46-56.
37 Davis SR, McCloud P, Strauss BJG \& Burger H. Testosterone enhances estradiol's effects on postmenopausal bone density and sexuality. Maturitas 199521 227-236.

38 Meyer WJ, Webb A, Stuart CA, Finkelstein JW, Lawrence B \& Walker PA. Physical and hormonal evaluation of transsexual patients: a longitudinal study. Archives of Sexual Behavior 198615 121-138.

39 Michel A, Mormont C \& Legros JJ. A psycho-endocrinological overview of transsexualism. European Journal of Endocrinology $2001145365-376$.

Received 9 May 2009

Accepted 4 June 2009 